\title{
Investigation on Stability and Galloping Characteristics of Iced Quad Bundle Conductor
}

\author{
X. $\operatorname{Liu}^{1,2 \dagger}$, G. $\operatorname{Min}^{2}$, C. $\operatorname{Sun}^{2}$ and M. $\mathrm{Cai}^{3}$ \\ ${ }^{1}$ State Key Laboratory of Mountain Bridge and Tunnel Engineering, Chongqing Jiaotong University, \\ Chongqing, 400074, China \\ ${ }^{2}$ School of Civil Engineering, Chongqing Jiaotong University, Chongqing, 400074, China \\ ${ }^{3}$ School of Architecture and Civil Engineering, Chengdu University, Chengdu, 610106, China \\ † Corresponding Author Email: cqdxlxh@126.com
}

(Received January 29, 2020; accepted June 4, 2020)

\begin{abstract}
The stability and galloping characteristics of iced quad bundle conductor are studied in this paper. Firstly, the aerodynamic coefficients of iced quad bundle conductor and single conductor under four different working conditions are obtained by wind tunnel test. Secondly, the equivalent aerodynamic coefficients at the central axis of the quad bundle conductor are obtained, and the equivalent aerodynamic coefficients are compared with the aerodynamic coefficients of each sub-conductor of the quad bundle conductor. Then, based on the Den Hartog instability mechanism and Nigol instability mechanism, the stable and unstable range of the equivalent coefficients of the quad bundle conductor are analyzed. Finally, the galloping characteristics of the quad bundle conductor are studied by combining with the equivalent aerodynamic coefficients at the central axis of quad bundle conductor. The results of the wind tunnel test show that the aerodynamic coefficients increase with the decreasing of the wind speed. The stability analyses show that the higher the wind speed is, the smaller the Den Hartog coefficient is the easier the Den Hartog' galloping would occur. Furthermore, the higher the wind speed is, the smaller the Nigol coefficient is, the easier the Nigol' galloping would occur. The analysis of galloping characteristics shows that when the conductor is located at stable state, the displacement in the $y$-axis direction would be much greater than the displacement in the z-axis direction.
\end{abstract}

Keywords: Quad bundle conductor; Aerodynamic coefficients; Stability; Galloping; Wind tunnel test.

\section{NOMENCLATURE}

cross-sectional area aerodynamic drag coefficient aerodynamic lift coefficient aerodynamic moment coefficient diameter of conductor

Young's modulus aerodynamic drag aerodynamic lift viscous damping in the $y$-axis direction viscous damping in the $z$-axis direction static tension length of conductor span length aerodynamic moment mass per unit length aerodynamic load in the $y$-axis direction $p_{z} \quad$ aerodynamic load in the $z$-axis direction

$U \quad$ average wind speed

$u(x, t) \quad$ displacements in the $x$-axis direction

$v(x, t)$ displacements in the $y$-axis direction

$w(x, t)$ displacements in the $z$-axis direction

$y(x) \quad$ static profile of conductor

$\alpha \quad$ angle of attack

$\alpha_{t} \quad$ relative angle of attack

$\alpha_{0} \quad$ initial angle of attack

$\delta k \quad$ kinetic energy of conductor

$\delta$ II kinetic energy of conductor

$\delta \mathrm{w}_{k}{ }^{\prime} \quad$ virtual work

$\theta(x, t) \quad$ displacements in the $\theta$-axis direction $\rho \quad$ air density 


\section{INTRODUCTION}

In order to solve the unbalanced supply and demand of electric power, a lot of long-span conductors have been established in China (Cai et al. 2019). While China is a large country with unique topographic and complicated engineering geology, under the action of winter monsoon, the surface of the conductor would be iced exceptionally easily. When the iced conductor is located at the certain angle of attack, due to the influences of aerodynamic lift, the iced conductor would to be galloping easily (Nigol et al. 1981a). Lee et al. (1992) and Zhang et al. (2000) closely explained the galloping of iced conductor is a kind of self-excited vibration with low-frequency and large-amplitude, which has strong geometric nonlinearity. The research of Braun et al. (2005) and Liu et al. (2019) expounded that the large-scale galloping of iced conductor would cause frequent tripping, power failure, collapsed tower and other accidents. Meanwhile the alternating tension caused by long-term and large-scale galloping would lead to serious accidents such as broken strands, wore hardware and damaged tower arm (Cai et al. 2019 and Liu et al. 2019), which are shown in Fig.1 and Fig.2.

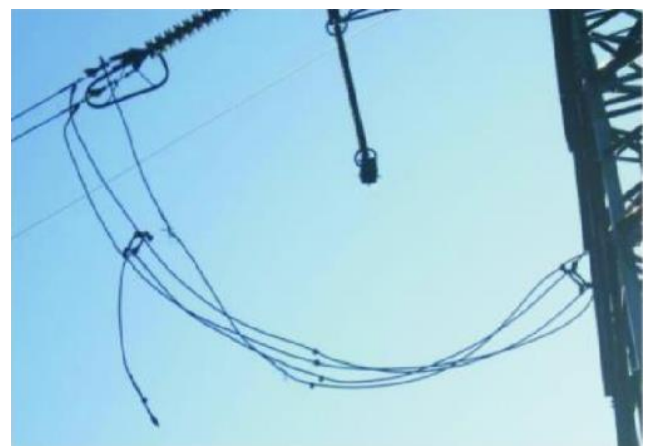

Fig. 1 Broken conductor.

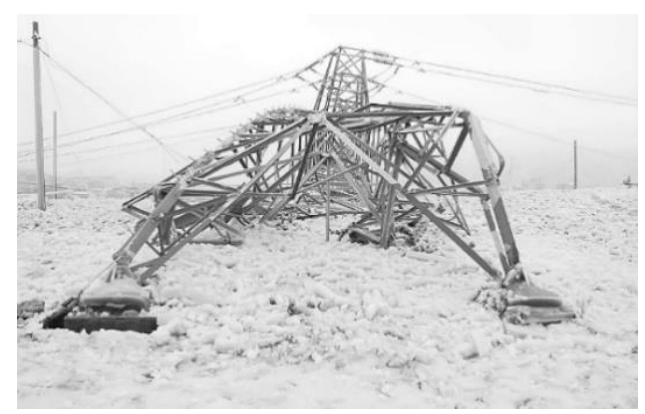

Fig. 2 Collapsed tower.

Based on these researches above, the study on galloping of iced conductor has a lot of application value in electric and civil engineering.

For the study of galloping characteristics of the iced conductor, aerodynamic coefficients are important physical parameters, which are used to analyze the galloping and stability characteristics of single and bundle conductor. Therefore, scholars have done a lot of work in this area for getting breakthrough results. And for the investigation on aerodynamic coefficients, there are only two commonly accepted research methods (Moghimi et al. 2018 and Wang et al. 2019), namely, numerical simulation method and wind tunnel test. As is known to us, the costs of wind tunnel test are extremely expensive but its results are accurate, since using different methods in different situations needs to be judged according to the actual situation. Peng et al. (2014) used the numerical simulation method to obtain the aerodynamic coefficients of iced bundle conductor, then obtained the aerodynamic coefficients of the iced bundle conductor again by wind tunnel test. By analyzing the results of these two methods, the rationality of numerical simulation method was proved. $\mathrm{Li}$ (1995) and $\mathrm{Li}$ (2000) also systematically investigated the dynamic and static aerodynamic coefficients of iced single and bundle conductor under different conditions through wind tunnel test, then the differences of dynamic and static aerodynamic coefficients are compared. In view of the lack of aerodynamic coefficients of iced quad bundle conductors, Zhang et al. (2011) carried out a static wind tunnel test on the aerodynamic characters of iced quad bundle conductors and some conclusions obtained by him have been applied to electric and civil engineering.

Based on numerical simulation method or wind tunnel test, the aerodynamic coefficients of iced conductor can be obtained in detail, then the galloping characteristics of iced conductor can be further studied. Liu et al. (2009) used finite element method to studied the galloping of iced conductor combined with wind tunnel test, which provides valuable advice for electric and civil engineering. Liu et al. (2013) studied the hysteresis phenomenon in the galloping of the D-shape iced conductor, and many meaningful conclusions were obtained. Based on the wind tunnel test, Lou et al (2014) studied the influences of iced thickness and initial iced accretion angle on the galloping characteristics of iced bundle conductor, and Lou et al. (2017) further investigated the critical wind speed of iced 6-bundled conductor combined with wind tunnel test.

Due to the randomness and diversity of iced shape of conductor, the currently existing aerodynamic coefficients could not meet the complex and changeable actual electric and civil engineering. Based on this concept, the wind tunnel test of iced quad bundle conductor is carried out in this paper, and the aerodynamic coefficients of quad bundle conductor obtained by this wind tunnel test can give some references for electric and civil engineering. Then, the influences of wind speed on the aerodynamic coefficients of quad bundle conductor is also studied systematically under four different working conditions. What' more, the equivalent aerodynamic coefficients at the central axis of quad 
bundle conductor are obtained by a reasonable method. In addition, the equivalent aerodynamic coefficients of iced quad bundle are compared with the aerodynamic coefficients of each sub-conductor of quad bundle conductor. Finally, the equivalent aerodynamic coefficients are fitted by Taylor' rules and galloping characteristics of iced quad bundle conductor is studied by combining the instability mechanism.

\section{Wind Tunnel Test Of ICED QuAd BUNDLE CONDUCTOR}

\subsection{Equipment of Wind Tunnel Test}

Although the different of topography, temperature, wind speed, and other factors would make iced type of conductor numerous and diverse, according to the investigation of Japanese scholars, the iced type of conductor is mainly crescent iced type (Cigre 2007). Meanwhile, in order to solve the unbalanced demand of electric energy, a lot of long-span quad bundle conductor have been launched in China (Cai et al. 2019). Based on these conclusions above, the stability and galloping characteristics of crescent iced quad bundle conductor are mainly studied in this paper.

In order to investigated the influences of wind speed on the aerodynamic coefficients of iced quad bundle conductor, the test is divided into four conditions according to the wind speed. The ice thicknesses of each sub-conductor of quad conductor both are $12 \mathrm{~mm}$. In order to facilitate research, the schematic diagram of the transverse segmental model of the quad bundle is established, which as shown in Fig.3. The ice is assumed evenly distributed on each subconductor of quad conductor.

According to the quality management requirements for large-scale wind tunnel test (GJB1452-1992), the wind tunnel test was conducted by the Institute of China Aerodynamics Research and Development Center in the $1.4 \mathrm{~m} \times 1.4 \mathrm{~m}$ wind tunnel.

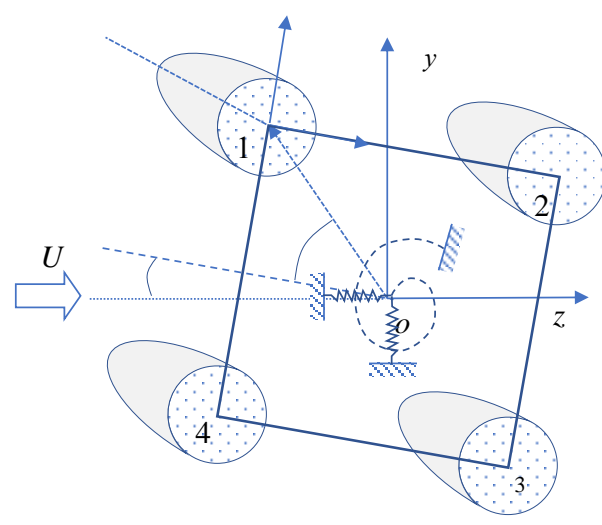

Fig. 3 Schematic diagram of the transverse segmental model of the quad bundle.

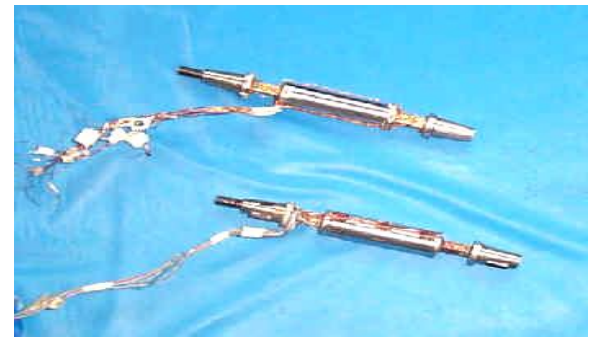

Fig. 4. Balance of TG0151A and TG0151B.

Table 1 Outward Sizes of TG0151A and TG0151B (mm)

\begin{tabular}{|c|c|c|c|c|}
\hline $\begin{array}{c}\text { Diameter } \\
(\mathrm{D})\end{array}$ & $\begin{array}{c}\text { Length } \\
\text { (L) }\end{array}$ & $\begin{array}{c}\text { Front } \\
\text { cone }\end{array}$ & $\begin{array}{c}\text { Back } \\
\text { cone }\end{array}$ & $\begin{array}{c}\text { Screw } \\
\text { hole }\end{array}$ \\
\hline 15 & 130 & $\begin{array}{c}1: 5, \\
\Phi 15 \times 21\end{array}$ & $\begin{array}{c}1: 5, \\
\Phi 15 \times 21\end{array}$ & M5 \\
\hline
\end{tabular}

Table 2 Measurement range and accuracy of TG0151A

\begin{tabular}{|c|c|c|c|c|c|c|}
\hline Project & $\mathrm{Y}$ & $\mathrm{MZ}$ & $\mathrm{X}$ & $\mathrm{MX}$ & $\mathrm{Z}$ & $\mathrm{MY}$ \\
\hline $\begin{array}{c}\text { Load range (N, } \\
\text { Nm) }\end{array}$ & 60 & 8 & 20 & 1 & 60 & 8 \\
\hline $\begin{array}{c}\text { Static } \\
\text { calibration (\%) }\end{array}$ & 0.3 & 0.3 & 0.5 & 0.3 & 0.3 & 0.3 \\
\hline Limit error (\%) & 0.9 & 0.9 & 1.5 & 0.9 & 0.9 & 0.9 \\
\hline
\end{tabular}

Table 3 Measurement range and accuracy of TG0151B

\begin{tabular}{|c|c|c|c|c|c|c|}
\hline Project & $\mathrm{Y}$ & $\mathrm{MZ}$ & $\mathrm{X}$ & $\mathrm{MX}$ & $\mathrm{Z}$ & $\mathrm{MY}$ \\
\hline $\begin{array}{c}\text { Load range (N, } \\
\text { Nm) }\end{array}$ & 60 & 8 & 20 & 1 & 60 & 8 \\
\hline $\begin{array}{c}\text { Static calibration } \\
(\%)\end{array}$ & 0.5 & 0.5 & 0.5 & 0.5 & 0.5 & 0.5 \\
\hline Limit error (\%) & 1.5 & 1.5 & 1.5 & 1.5 & 1.5 & 1.5 \\
\hline
\end{tabular}

In this wind tunnel test, two types of balances are required, namely TG0151A and TG0151B. And the two types of balances are used to measure aerodynamic drag, lift, and moment of iced quad bundle conductor. The picture of these two balances of TG0151A and TG0151B is shown in Fig.4, and the dimensions, ranges and accuracy of the two types of balance are listed in Tables. 1 to 3 .

The model of quad bundle conductor is 4XLGJ$400 / 50$ and each sub-conductor has the same structural parameters. The diameter of all the subconductors is $27.6 \mathrm{~mm}$ and the type of FJZ-400 spacer is used between the quad bundle conductor, which is to make the spacing between the adjacent sub-conductors be $450 \mathrm{~mm}$, so the sub-conductor would not be entangled when they are galloping.

The model of the conductor is shown in Fig.5, and the model of iced shape is shown in Fig.6. The main content of this wind tunnel test is to obtain the aerodynamic coefficients of quad bundle conductor and single conductor under different wind speed. 
The change range of $\alpha$ is $0^{\circ}$ to $360^{\circ}$, and the direction of turning for force-measured device is clockwise.

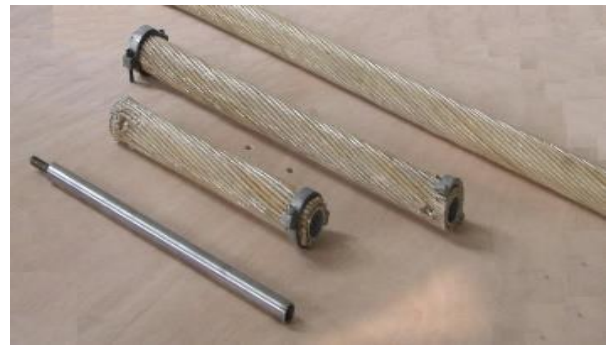

Fig. 5. Model of conductor.

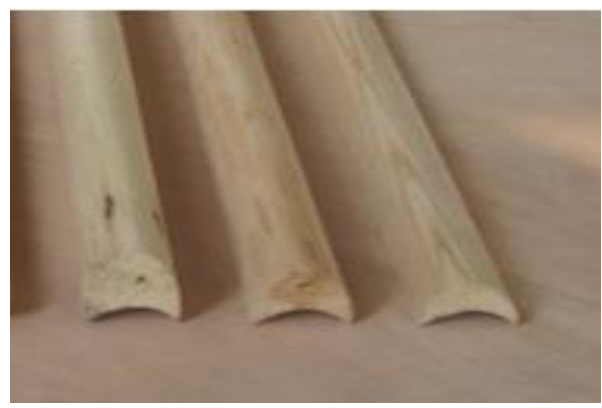

Fig. 6. Model of iced shape.

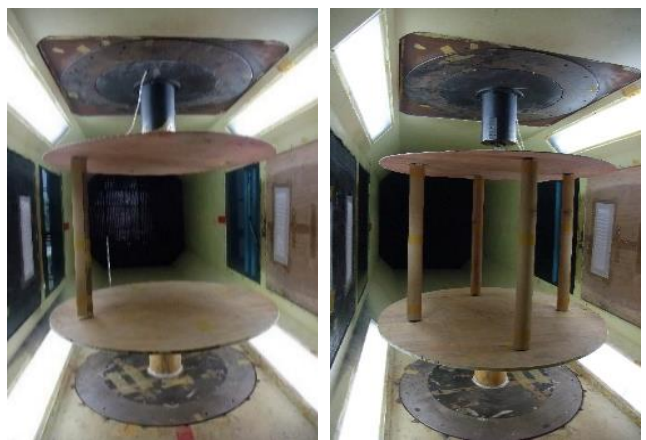

Fig. 7. Force-measured device of single conductor and quad bundle conductor.

The pictures of static traverse force-measured device of quad bundle conductor and single conductor are shown in Fig.7 above. The aerodynamic coefficients measured by this test including aerodynamic drag, lift, and moment coefficient, then the dimensionless aerodynamic parameters are defined as follows:

$C_{D}=\frac{2 F_{D}}{\rho U^{2} L D}, C_{L}=\frac{2 F_{L}}{\rho U^{2} L D}, C_{M}=\frac{2 M_{z}}{\rho U^{2} L D^{2}}$

Where $F_{D}, F_{L}$, and $M_{\mathrm{Z}}$ are the drag, lift, and moment of conductor respectively. $\rho$ is the air density, $U$ is the average wind speed, $L$ is the length of conductor and $D$ is the diameter of conductor.

\subsection{Aerodynamic characteristics of quad bundle conductor}

In this wind tunnel test, the aerodynamic coefficients of crescent iced quad bundle conductor with $12 \mathrm{~mm}$ ice thickness are tested under the wind speed of $10 \mathrm{~m} / \mathrm{s}, 12 \mathrm{~m} / \mathrm{s}, 14 \mathrm{~m} / \mathrm{s}$ and $18 \mathrm{~m} / \mathrm{s}$ respectively. The aerodynamic coefficients of each sub-conductor of quad bundle conductor are shown in Fig. 8 to Fig.10.

This test considered the influences of different wind speed on the aerodynamic characteristics of each sub-conductor of quad bundle conductor. Form Fig.8 to Fig.10, it can obtain that the static aerodynamic characteristics of iced quad bundle conductor under various wind speeds.

(1) When $\alpha$ is less than $40^{\circ}, C_{L}$ shows an upward trend. When the $\alpha$ is located at the range of $40^{\circ}$ to $120^{\circ}, C_{L}$ shows a downward trend. When the $\alpha$ is located at the range of $120^{\circ}$ to $160^{\circ}, C_{L}$ has an upward trend again, but the upward trend is more obvious than those when $\alpha$ is located at the range of $40^{\circ}$ to $120^{\circ}$. The trend of $C_{L}$ is antisymmetric when $\alpha$ is located at the leeward $180^{\circ}$ and when $\alpha$ is located at the windward $180^{\circ}$.

(2) When $\alpha$ keeps constant, it can obtain that $C_{D}$ of each sub-conductor decreases with the increasing of wind speed. For the different location of each subconductor, there are different wake effects, and the sudden drop location of $C_{D}$ for each sub-conductor of iced quad bundle is also different. $C_{D}$ of subconductor 1 is affected by the wake effects of subconductor 2 when $\alpha$ is located at the range of $130^{\circ}$.to $135^{\circ} \cdot C_{D}$ of sub-conductor 3 drops suddenly when $\alpha$ is $45^{\circ}$ influenced by the wake effects of subconductor 2. $C_{D}$ of sub-conductor 4 is affected by the wake effects of sub-conductor 1,2 and 3 when $\alpha$ is about $45^{\circ}, 90^{\circ}$ and $135^{\circ}$ respectively.

(3) When $\alpha$ is less than $45^{\circ}, C_{M}$ increases with the increasing of $\alpha$, while when $\alpha$ is greater than $45^{\circ}, C_{M}$ decreases with the increasing of $\alpha$. The trend of $C_{M}$ is antisymmetric when $\alpha$ is located at the latter $180^{\circ}$ and when $\alpha$ is located at the former $180^{\circ}$.

\subsection{Equivalent Aerodynamic Coefficient of Quad Bundle Conductor}

For the different location of each sub-conductor of quad bundle would result in different wake effects, so the variation of aerodynamic coefficients of each sub-conductor with $\alpha$ can't accurately reflect the variation of the equivalent aerodynamic coefficients at the central axis of quad bundle conductor with $\alpha$. In order to obtain the variation of the equivalent aerodynamic coefficients at the central axis of iced quad bundle conductor with $\alpha$, the definitions of equivalent lift and drag coefficient of quad bundle conductor are shown in follows.

$C_{L}^{N}(t)=\frac{1}{N} \sum_{i=1}^{N} C_{L}^{i}(t)$

$C_{D}^{N}(t)=\frac{1}{N} \sum_{i=1}^{N} C_{D}^{i}(t)$ 


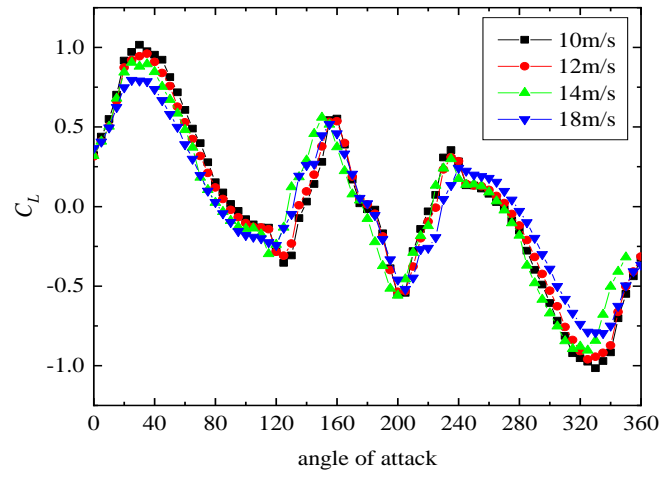

(a) Lift coefficient of sub-conductor 1

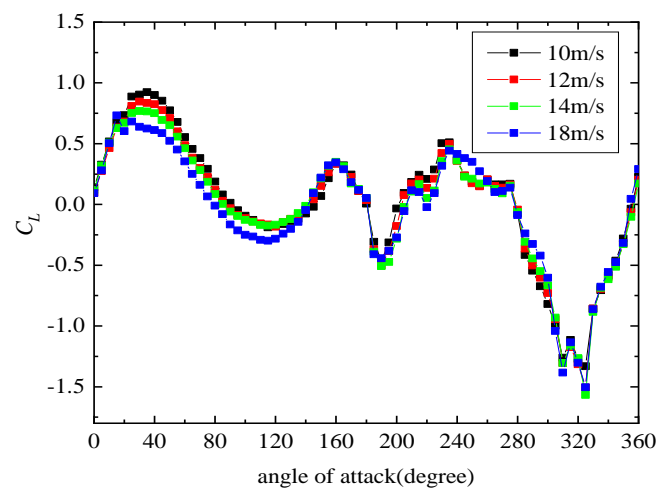

(b) Lift coefficient of sub-conductor 2

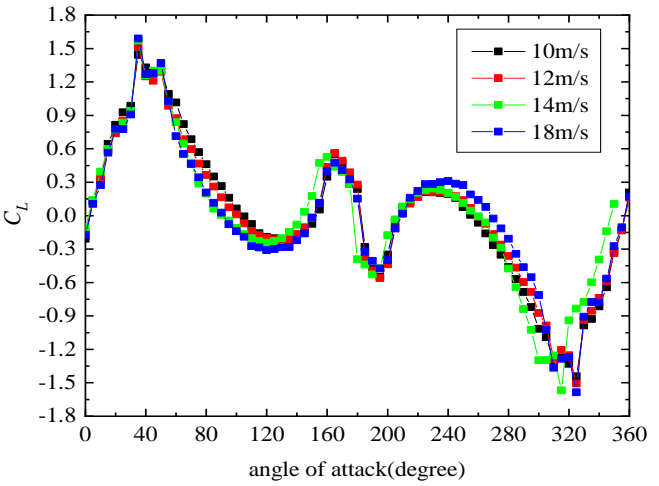

(c) Lift coefficient of sub-conductor 3

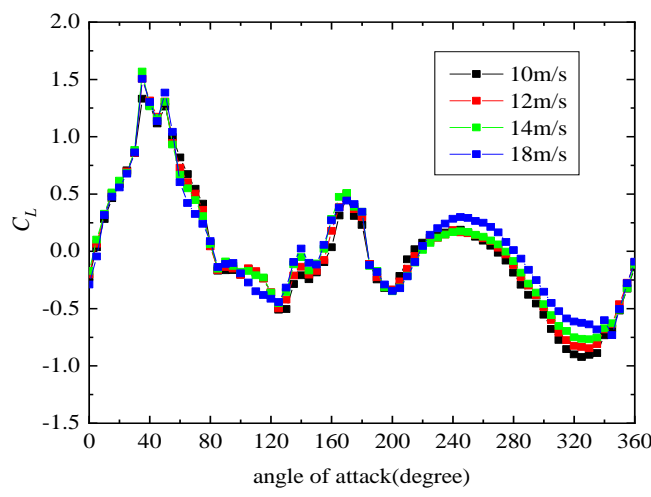

(d) Lift coefficient of sub-conductor 4

Fig. 8. Lift coefficient of iced quad bundle conductor under various wind speeds.

Where the physical meaning of Eq. (2a) and Eq. (2b) is that the equivalent aerodynamic lift coefficient is equal to the average value of lift coefficient of each sub-conductor, and the equivalent aerodynamic drag coefficient is equal to the average value of drag coefficient of each sub-conductor.

The equivalent moment coefficient at the central axis of quad bundle conductor is defined as:

$$
C_{M}^{N}(t)=\frac{1}{N}\left[C_{M, S}^{N}(t)+C_{M, D}^{N}(t)+C_{M, L}^{N}(t)\right]
$$

Where $C_{M, S}^{N}(t), C_{M, D}^{N}(t), C_{M, L}^{N}(t)$ respectively represents the contribution of the moment, drag, and lift of each sub-conductor to the equivalent moment coefficient. Meanwhile, for the iced quad bundle conductor $N$ is 4 , then it can obtain that

$$
C_{M, S}^{4}(t)=\sum_{i=1}^{4} C_{M}^{i}(t)
$$

$$
\begin{aligned}
& C_{M, D}^{4}=\frac{1}{\sqrt{2}}\left[C_{D}^{1}(t)-C_{D}^{3}(t)\right] \sin \left(\frac{\pi}{4}+\alpha\right)- \\
& \frac{1}{\sqrt{2}}\left[C_{D}^{4}(t)-C_{D}^{2}(t)\right] \cos \left(\frac{\pi}{4}+\alpha\right)
\end{aligned}
$$

$$
\begin{aligned}
& C_{M, L}^{4}=\frac{1}{\sqrt{2}}\left[C_{L}^{1}(t)-C_{L}^{3}(t)\right] \sin \left(\frac{\pi}{4}+\alpha\right)- \\
& \frac{1}{\sqrt{2}}\left[C_{L}^{4}(t)-C_{L}^{2}(t)\right] \cos \left(\frac{\pi}{4}+\alpha\right)
\end{aligned}
$$

Due to the complexity of the mathematical symbols of equivalent aerodynamic coefficients, $C_{L}, C_{D}$ and $C_{M}$ are also used to represent the equivalent aerodynamic lift, drag, and moment coefficients of the iced quad bundle conductor. Then, the aerodynamic coefficients in Fig.8 to 10 are sorted out according to the definitions of Eq. (2a), Eq. (2b) and Eq. (3), then the equivalent aerodynamic coefficients of quad bundle conductor are obtained which are shown in Fig.11 and Fig.13.

It can also be seen from Fig.11 to Fig.13 that the influences of wind speed on the aerodynamic coefficient is not very obvious.

\subsection{Analysis of Instability}

According to the Den Hartog instability mechanism of galloping (Den Hartog 1932), the stability of iced conductor can be determined according to Eq. (7).

$$
\text { Den }=\frac{\partial C_{L}}{\partial \alpha}+C_{D}<0
$$




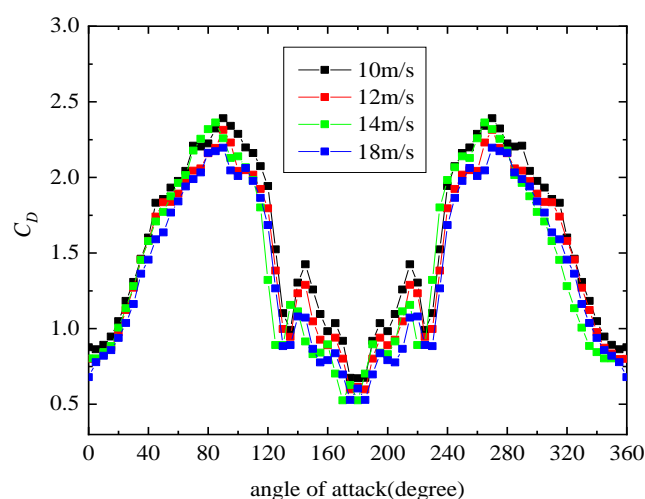

(a) Drag coefficient of Sub-conductor 1

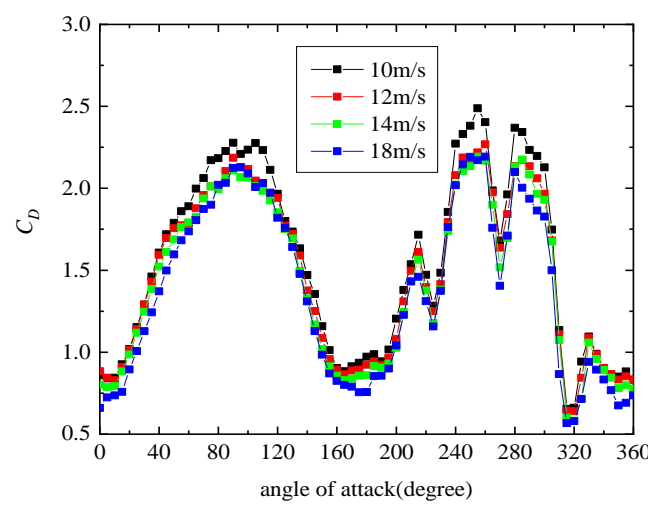

(b) Drag coefficient of Sub-conductor 2

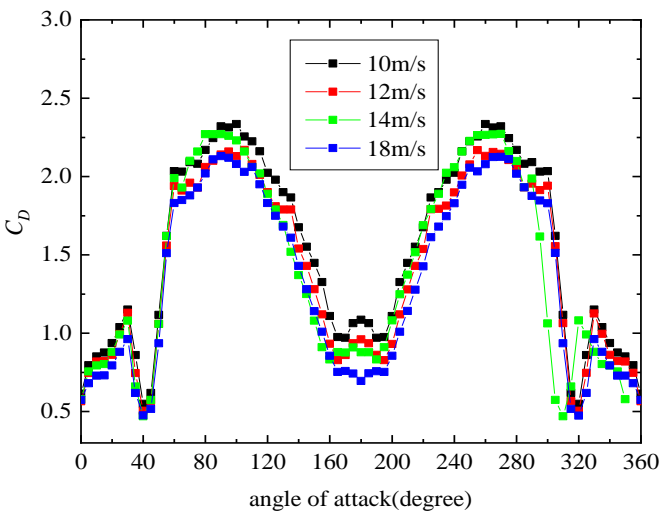

(c) Drag coefficient of Sub-conductor 3

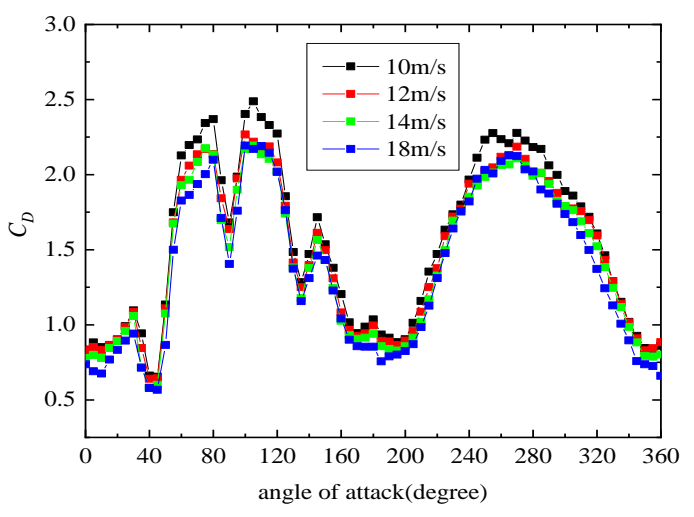

(d) Drag coefficient of Sub-conductor 4

Fig. 9. Drag coefficient of iced quad bundle conductor under various wind speeds.

Where Den is the Den Hartog coefficient, and if Den is less than zero, galloping would occur for iced conductor. It can be also seen form Eq. (7) that the aerodynamic coefficients affecting Den Hartog coefficient are $C_{D}$ and $C_{L}$.

Take the first derivative of $C_{L}$ and add it to $C_{D}$ to obtain the Den Hartog coefficient, which is shown in Fig.12.

It can be seen from Fig.14 that the unstable range of $\alpha$ of quad bundle conductor are located at the range of $50^{\circ}$ to $80^{\circ}, 130^{\circ}$ to $180^{\circ}, 180^{\circ}$ to $230^{\circ}$ and $280^{\circ}$ to $310^{\circ}$ respectively. With the increasing of wind speed, the values of the Den Hartog coefficient of iced quad bundle and single conductor decreases, that is to say, the higher the wind speed is, the more likely the Den Hartog galloping would occur. Comparing the Den Hartog coefficient in Fig.14 of single conductor with the Den Hartog coefficient of quad bundle conductor in Fig.15, it can be found that the general trend of Fig.14 is almost the same as that of Fig.15, but the place where the maximum value is obtained is different. The den Hartog coefficient of quad bundle conductor reaches the maximum value at both ends of curve and the minimum value in the middle of curve. While the Den Hartog coefficient of single conductor reaches the maximum when $\alpha$ is $150^{\circ}$ or $220^{\circ}$, and reaches the minimum value in the middle of curve.

According to the Nigol instability mechanism (Nigol 1981b), the necessary conditions for the occurrence of Nigol galloping can be expressed as follows.

$N i=\frac{\partial C_{M}}{\partial \alpha}<0$

Taking the first derivative of $C_{M}$ can obtain the Nigol coefficient, which is shown in Fig.16 to Fig.17.

It can be seen from Fig.16 to Fig. 17 that the unstable range of Nigol galloping for quad bundle conductor is wider than that for single conductor, because most of the values of Nigol coefficient in Fig.16 to Fig.17 are negative, which also directly shows that the torsional effect of iced conductor could not be ignored in the actual working condition. The effect of wind speed on Nigol coefficient is similar to that of wind speed on Den Hartog coefficient, that is, with the increasing of wind speed, the Nigol coefficient would decreases, and the higher the wind speed, the more likely the Nigol galloping would occur. 


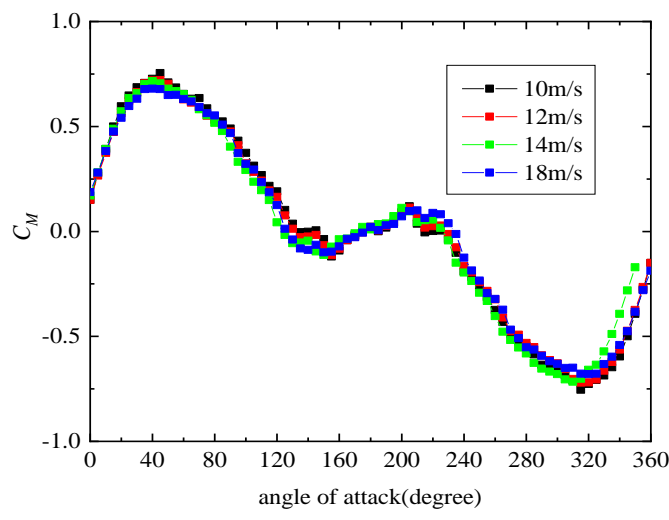

(a) Moment coefficient of Sub-conductor 1

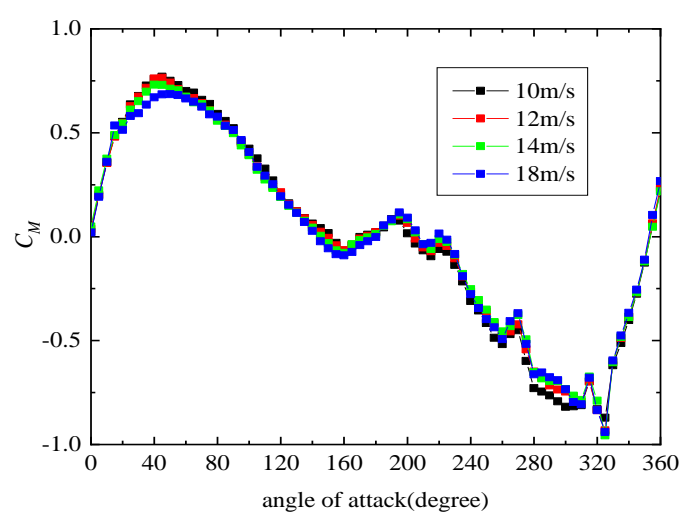

(b) Moment coefficient of Sub-conductor 2

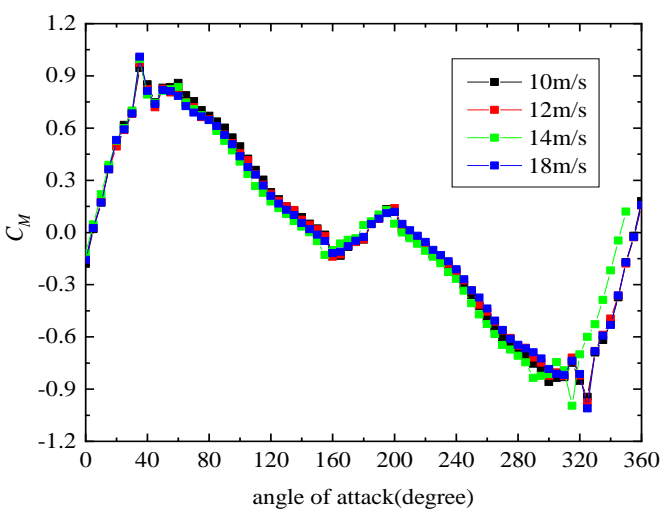

(c) Moment coefficient of Sub-conductor 3

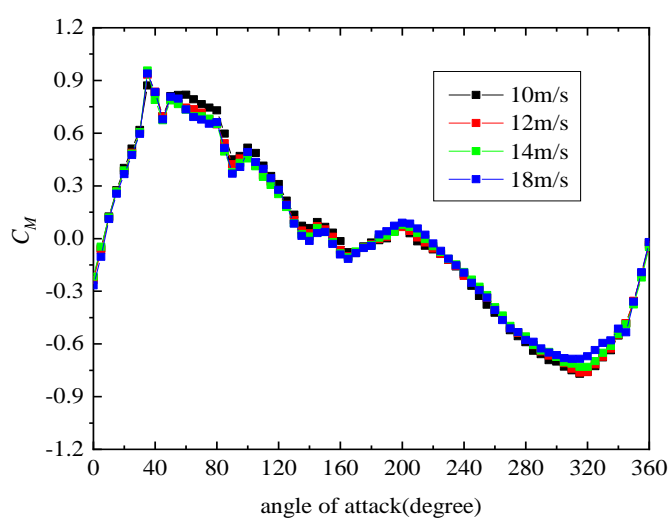

(d) Moment coefficient of Sub-conductor 4

Fig. 10. Moment coefficient of iced quad bundle conductor under various wind speeds.

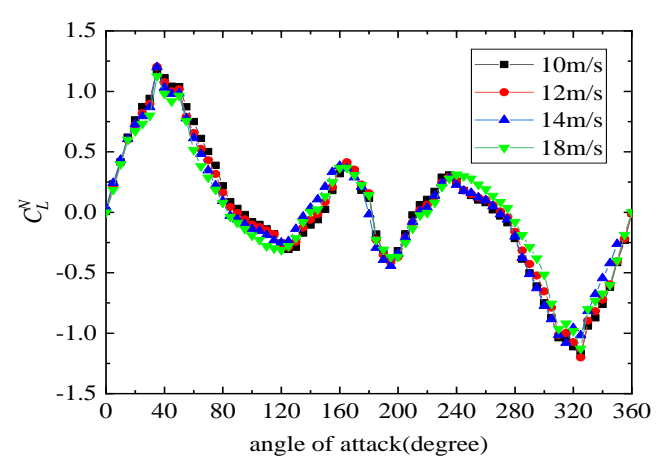

Fig. 11. Equivalent lift coefficients.

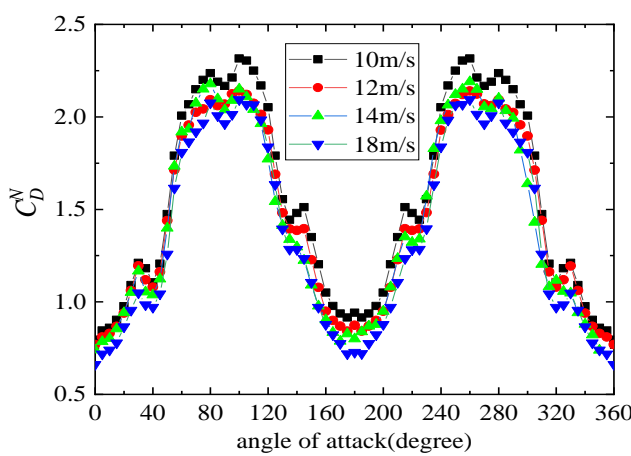

Fig. 12. Equivalent drag coefficients.

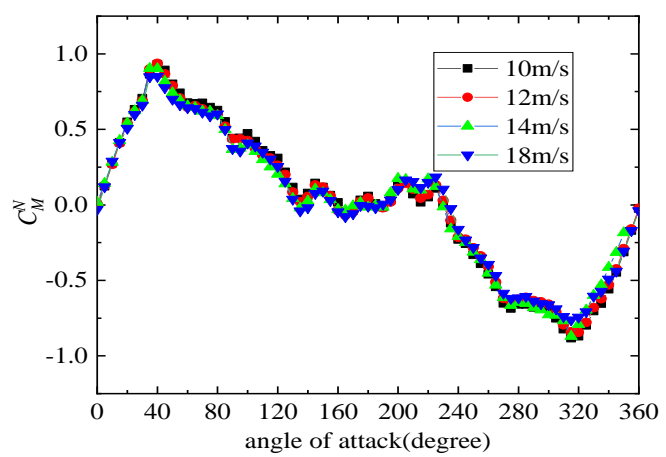

Fig. 13. Equivalent moment coefficients.

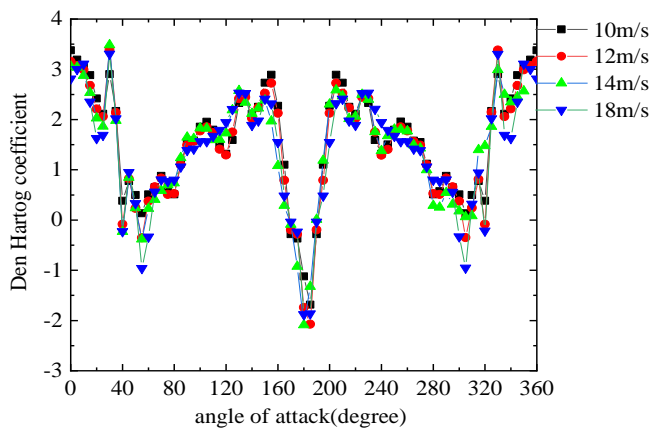

Fig. 14. Den Hartog coefficient of iced quad bundle conductor. 


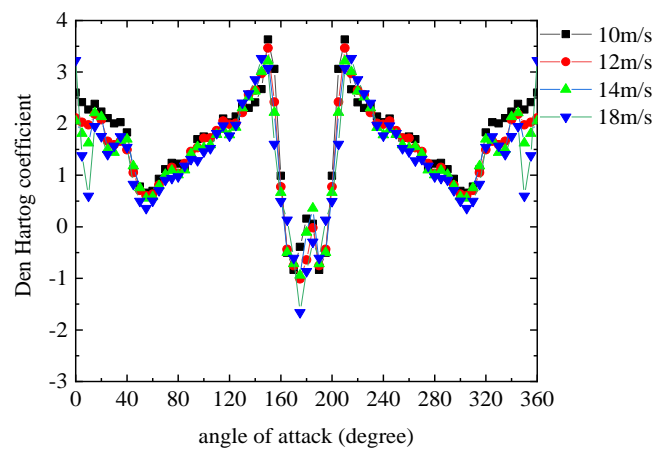

Fig. 15. Den Hartog coefficient of iced single conductor.

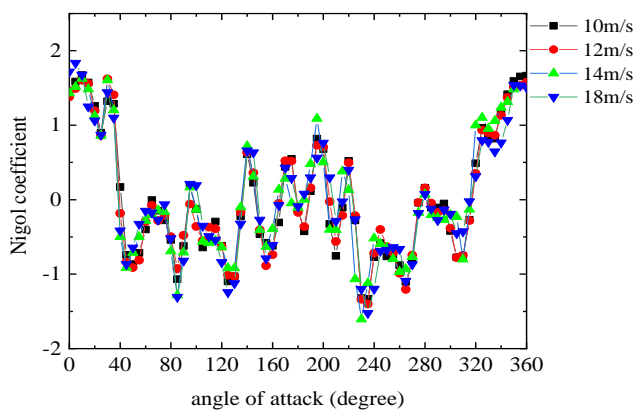

Fig. 16. Nigol coefficient of quad bundle conductor.

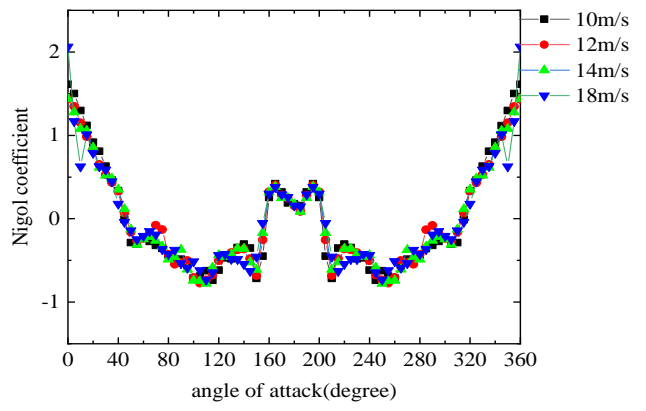

Fig. 17. Nigol coefficient of single conductor.

\section{The EquATion Of Free Vibration}

\subsection{Vibration model of conductor}

The mathematical model of single conductor is established as shown in Fig.18. The two ends of the conductor are constrained by fixed supports. $\Gamma_{1}$ is the equilibrium profile under the action of gravity, while $\Gamma_{2}$ is the dynamic profile under the action of gravity and other external loads.

When the equilibrium profile changes under the action of other external loads, the corresponding micro element length becomes $\mathrm{d} s^{\mathrm{m}}$, then extensional strain in the conductor is

$$
\begin{aligned}
& \varepsilon=\frac{\mathrm{d} s-\mathrm{d} s^{m}}{\mathrm{~d} s}=\frac{1}{l} \int_{0}^{l} \frac{\mathrm{d} x}{\mathrm{~d} s} \frac{\partial u}{\partial s}+\frac{1}{2}\left(\frac{\partial u}{\partial s}\right)^{2}+ \\
& \frac{\mathrm{d} y}{\mathrm{~d} s} \frac{\partial v}{\partial s}+\frac{1}{2}\left(\frac{\partial v}{\partial s}\right)^{2}+\frac{\mathrm{d} z}{\mathrm{~d} s} \frac{\partial w}{\partial s}+\frac{1}{2}\left(\frac{\partial w}{\partial s}\right)^{2} \mathrm{~d} s
\end{aligned}
$$

Where $u(x, t), v(x, t)$ and $w(x, t)$ are the displacements measured form the equilibrium profile in the $x$-axis, $y$-axis and z-axis direction respectively.

The vibration equation of single-span conductor can be obtained by the variational principle for Hamiltonian

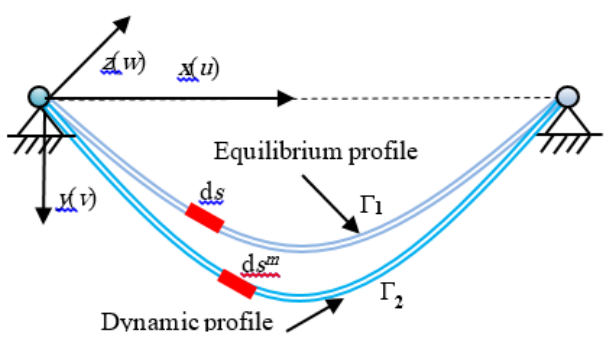

Fig. 18. Mathematical model of conductor.

$\int \delta k-\int \delta \Pi+\int \delta \mathrm{w}_{k}^{\prime}=0$

Where $\delta k$ is the kinetic energy of conductor, $\delta$ II is the potential energy of conductor, and $\delta \mathrm{w}_{\mathrm{k}}{ }^{\prime}$ is the virtual work is associated with gravity, external and damping forces.

Ignoring displacement in the $x$-axis direction of conductor and according to Eq. (10), it can obtain that

$H \frac{\partial^{2} v}{\partial x^{2}}+\frac{E A}{l}\left(\frac{\mathrm{d}^{2} y}{\mathrm{~d} x^{2}}+\frac{\partial^{2} v}{\partial x^{2}}\right) \int_{0}^{l} \frac{\partial u}{\partial x}+\frac{\mathrm{d} y}{\mathrm{~d} x} \frac{\partial v}{\partial x}+$
$\frac{1}{2}\left[\left(\frac{\partial v}{\partial x}\right)^{2}+\left(\frac{\partial w}{\partial x}\right)^{2}\right] \mathrm{d} x=m \ddot{v}+f_{y} \dot{v}-p_{y}$

$H \frac{\partial^{2} w}{\partial x^{2}}+\frac{E A}{l} \frac{\partial^{2} w}{\partial x^{2}} \int_{0}^{l} \frac{\partial u}{\partial x}+\frac{\mathrm{d} y}{\mathrm{~d} x} \frac{\partial v}{\partial x}+$

$\frac{1}{2}\left[\left(\frac{\partial v}{\partial x}\right)^{2}+\left(\frac{\partial w}{\partial x}\right)^{2}\right] \mathrm{d} x=m \ddot{w}+f_{z} \dot{w}-p_{z}$

Where $f_{y}, f_{z}$ are the viscous damping coefficients in the $y$ - and $z$-co-ordinate direction respectively. $P_{y}(x$ $t), P_{z}(x, t)$ are the aerodynamic loads per unit length in the $y$-axis and z-axis direction of conductor respectively. $m$ is mass per unit length. $H$ is static tension, $E$ is Young's modulus, $A$ is cross-sectional area and $y(x)$ represents static profile of conductor, respectively.

The vibration displacement of the conductor can be written as

$u(x, t)=\psi_{1}(x) q_{1}(t)$ 
X. Liu et al. / JAFM, Vol. 14, No. 1, pp. 117-129, 2021.

$v(x, t)=\psi_{2}(x) q_{2}(t)$

$w(x, t)=\psi_{3}(x) q_{3}(t)$

where $\psi_{1}(x), \psi_{2}(x)$ and $\psi_{3}(x)$ are mode shapes, $q_{1}(x)$, $q_{2}(x)$ and $q_{3}(x)$ are vibration functions.

Substituting Eq. (12) into Eq. (11) leads to

$\frac{E A}{l}\left(y^{\prime \prime}+\psi_{2}^{\prime \prime} q_{2}\right) \int_{0}^{l} \psi_{1}^{\prime} q_{1}+y^{\prime} \psi_{2}^{\prime} q_{2}+\frac{1}{2}\left(\psi_{2}^{\prime 2} q_{2}^{2}+\right.$

$\left.\psi_{3}^{\prime 2} q_{3}^{2}\right) \mathrm{d} x=m \psi_{2} \ddot{q}_{2}+f_{v} \psi_{2} \dot{q}_{2}-p_{y}-H \psi_{2}^{\prime \prime} q_{2}$

$\frac{E A}{l} \psi_{3}^{\prime \prime} q_{3} \int_{0}^{l} \psi_{1}^{\prime} q_{1}+y^{\prime} \psi_{2}^{\prime} q_{2}+\frac{1}{2}\left(\psi_{2}^{\prime 2} q_{2}^{2}+\right.$

$\left.\psi_{3}^{\prime 2} q_{3}^{2}\right) \mathrm{d} x=m \psi_{3} \ddot{q}_{3}+f_{z} \psi_{3} \dot{q}_{3}-p_{z}-H \psi_{3}^{\prime \prime} q_{3}$

By multiplying Eq. (13) by $\psi_{2}$ and integrating the outcomes over $x \in[0, l]$, the ordinary differential galloping equation of iced conductor in $y$-axis direction can be obtained

$b_{1} \ddot{q}_{2}+b_{2} \dot{q}_{2}+b_{4} q_{2}+b_{5} q_{2}^{2}+$

$b_{6} q_{3}^{2}+b_{8} q_{2}^{3}+b_{9} q_{2} q_{3}^{2}=p_{2}$

Where

$b_{1}=\int_{0}^{l} m \psi_{2}^{2} \mathrm{~d} x, b_{2}=\int_{0}^{l} f_{y} \psi_{2}^{2} \mathrm{~d} x$,

$b_{3}=-\int_{0}^{l}\left(\frac{E A}{l} y^{\prime \prime} \int_{0}^{l} \psi_{1}^{\prime} \mathrm{d} x\right) \psi_{2} \mathrm{~d} x$,

$b_{4}=\int_{0}^{l}\left(-\frac{E A}{l} y^{\prime \prime} \int_{0}^{l} y^{\prime} \psi_{2}^{\prime} \mathrm{d} x-H \psi_{2}^{\prime \prime}\right) \psi_{2} \mathrm{~d} x$,

$\left.b_{5}=-\int_{0}^{l}\left\{\left(\frac{E A}{2 l} y^{\prime \prime} \int_{0}^{l} \psi_{2}^{\prime 2} \mathrm{~d} x\right)+\frac{E A}{l} \psi_{2}^{\prime \prime} \int_{0}^{l} y^{\prime} \psi_{2}^{\prime} \mathrm{d} x\right)\right\} \psi_{2} \mathrm{~d} x$,

$b_{6}=-\int_{0}^{l}\left(\frac{E A}{2 l} y^{\prime l} \int_{0}^{l} \psi_{3}^{\prime 2} \mathrm{~d} x\right) \psi_{2} \mathrm{~d} x$,

$b_{7}=-\int_{0}^{l}\left(\frac{E A}{l} \psi_{2}^{\prime \prime} \int_{0}^{l} \psi_{1}^{\prime} \mathrm{d} x\right) \psi_{2} \mathrm{~d} x$,

$b_{8}=-\int_{0}^{l}\left(\frac{E A}{2 l} \psi_{2}^{\prime \prime} \int_{0}^{l} \psi_{2}^{\prime 2} \mathrm{~d} x\right) \psi_{2} \mathrm{~d} x$

$b_{9}=-\int_{0}^{l}\left(\frac{E A}{2 l} \psi_{2}^{\prime \prime} \int_{0}^{l} \psi_{3}^{\prime 2} \mathrm{~d} x\right) \psi_{2} \mathrm{~d} x, p_{2}=\int_{0}^{l} p_{y} \psi_{2} \mathrm{~d} x$,

By multiplying Eq. (14) by $\psi_{3}$ and integrating the outcomes over $x \in[0, l]$, the ordinary differential galloping equation of the iced conductor in $z$-axis direction can be obtained

$c_{1} \ddot{q}_{3}+c_{2} \dot{q}_{3}+c_{3} q_{3}+c_{5} q_{2} q_{3}+c_{6} q_{2}^{2} q_{3}+c_{7} q_{3}^{3}=p_{3}$

Where

$c_{1}=\int_{0}^{l} m \psi_{3}^{2} \mathrm{~d} x, c_{2}=\int_{0}^{l} f_{z} \psi_{3}^{2} \mathrm{~d} x, c_{3}=\int_{0}^{l}\left(-H \psi_{3}^{\prime \prime}\right) \psi_{3} \mathrm{~d} x$,
$c_{4}=-\int_{0}^{l}\left(\frac{E A}{l} \psi_{3}^{\prime \prime} \int_{0}^{l} \psi_{1}^{\prime} \mathrm{d} x\right) \psi_{3} \mathrm{~d} x$,

$c_{5}=-\int_{0}^{l}\left(\frac{E A}{l} \psi_{3}^{\prime \prime} \int_{0}^{l} y^{\prime} \psi_{2}^{\prime} \mathrm{d} x\right) \psi_{3} \mathrm{~d} x$,

$c_{6}=-\int_{0}^{l}\left(\frac{E A}{2 l} \psi_{3} \int_{0}^{l} \psi_{2}^{\prime 2} \mathrm{~d} x\right) \psi_{3} \mathrm{~d} x$

$c_{7}=-\int_{0}^{l}\left(\frac{E A}{2 l} \psi_{3}^{\prime \prime} \int_{0}^{l} \psi_{3}^{\prime 2} \mathrm{~d} x\right) \psi_{3} \mathrm{~d} x, p_{3}=\int_{0}^{l} p_{z} \psi_{3} \mathrm{~d} x$,

\subsection{Aerodynamic Loads on Iced Quad Bundle Conductor}

In this paper, for the iced single-span conductor, only the Den Hartog instability mechanism is considered. The relative wind speed and wind direction caused by the relative motion of the conductor are shown in Fig.19. Form Fig.19, $\alpha_{t}$ is the relative wind angle of attack associated with the movement in the $y$-axis and $\theta$-axis directions of the conductor.

For the displacement in the $\theta$-axis direction is very small, the influences of the displacement in the $\theta$ axis direction on the galloping characteristics of iced conductor is not considered in this paper. Based on this concept, the iced conductor is subjected to the aerodynamic loads in two directions: $P_{y}, P_{z}$ are the aerodynamic loads per unit length, acting on the conductor in the $y$-axis and z-axis directions respectively. Then, it can obtain that

$$
\begin{aligned}
& p_{y}=F_{\mathrm{L}} \cos \left(\alpha_{t}\right)-F_{\mathrm{D}} \sin \left(\alpha_{t}\right)=0.5 \rho U^{2} D C_{y}(\alpha) \\
& p_{z}=F_{\mathrm{L}} \sin \left(\alpha_{t}\right)+F_{\mathrm{D}} \cos \left(\alpha_{t}\right)=0.5 \rho U^{2} D C_{z}(\alpha)
\end{aligned}
$$

Where $C_{y}(\alpha), C_{z}(\alpha)$ are aerodynamic coefficients fitted with a cubic curve in the $y$-axis and $z$-axis direction, respectively.

The Taylor expansion of $C_{y}(\alpha)$ at $\alpha=0$ is carried out, and the higher order small quantities of order 4 and above 4 are omitted

$$
\begin{aligned}
& C_{y}(\alpha)=\left(C_{y} \mid \alpha=0\right)+\left(\frac{\partial C_{y}}{\partial \alpha} \mid \alpha=0\right) \alpha \\
& +\left(\frac{\partial^{2} C_{y}}{\partial \alpha^{2}} \mid \alpha=0\right) \alpha^{2}+\left(\frac{\partial^{3} C_{y}}{\partial \alpha^{3}} \mid \alpha=0\right) \alpha^{3}+\mathrm{O}\left(\alpha^{4}\right)
\end{aligned}
$$

The right terms of Eq. (19) can be expressed as

$\left(C_{y} \mid \alpha=0\right)=C_{L} \cos (\alpha)+C_{D} \sin (\alpha)=\left(C_{L} \mid \alpha=0\right)(20 \mathrm{a})$

$$
\begin{aligned}
& \left(\frac{\partial C_{y}}{\partial \alpha} \mid \alpha=0\right)=\left(\left(\frac{\partial C_{L}}{\partial \alpha} \cos \alpha-C_{L} \sin \alpha+\right.\right. \\
& \left.\left.\frac{\partial C_{D}}{\partial \alpha} \sin \alpha+C_{D} \cos \alpha\right) \mid \alpha=0\right)=\frac{\partial C_{L}}{\partial \alpha}+C_{D}
\end{aligned}
$$




$$
\begin{aligned}
& \left.\frac{\partial^{2} C_{y}}{\partial \alpha^{2}} \mid \alpha=0\right)=\left(\left(\frac{\partial^{2} C_{L}}{\partial \alpha^{2}} \cos \alpha-2 \frac{\partial C_{L}}{\partial \alpha} \sin \alpha-\right.\right. \\
& C_{L} \cos \alpha+\frac{\partial^{2} C_{D}}{\partial \alpha^{2}} \cos \alpha+2 \frac{\partial C_{D}}{\partial \alpha} \cos \alpha- \\
& \left.\left.C_{D} \sin \alpha\right) \mid \alpha=0\right)=\frac{\partial^{2} C_{L}}{\partial \alpha^{2}}-C_{L}+2 \frac{\partial C_{D}}{\partial \alpha} \\
& \left(\frac{\partial^{3} C_{y}}{\partial \alpha^{3}} \mid \alpha=0\right)=\left(\left(\frac{\partial^{3} C_{L}}{\partial \alpha^{3}} \cos \alpha-3 \frac{\partial^{2} C_{L}}{\partial \alpha^{2}} \sin \alpha-\right.\right. \\
& 3 \frac{\partial C_{L}}{\partial \alpha} \cos \alpha+C_{L} \sin \alpha+\frac{\partial^{3} C_{D}}{\partial \alpha^{3}} \sin \alpha+ \\
& \left.\left.3 \frac{\partial^{2} C_{D}}{\partial \alpha^{2}} \cos \alpha-3 \frac{\partial C_{D}}{\partial \alpha} \sin \alpha-C_{D} \cos \alpha\right) \mid \alpha=0\right) \\
& =\frac{\partial^{3} C_{L}}{\partial \alpha^{3}}-3 \frac{\partial C_{L}}{\partial \alpha}+3 \frac{\partial^{2} C_{D}}{\partial \alpha^{2}}-C_{D}
\end{aligned}
$$

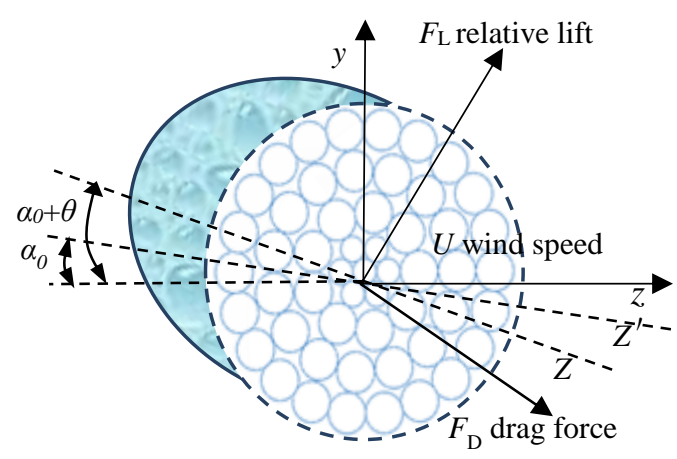

(a) Cross-sectional model of iced conductor

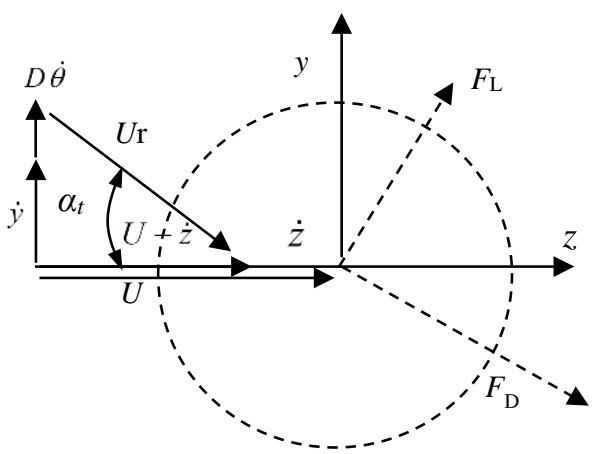

(b) Relative flow in the quasi-steady assumption

Fig. 19. Cross-sectional model of iced conductor and relative flow.

Since the constant term in Eq (20a) would not affect the galloping characteristics of the iced quad bundle conductor. If the constant term is ignored and Eq. (20) is substituted into Eq. (19), then it can be obtained that

$$
\begin{aligned}
& C_{y}=\left(\frac{\partial C_{L}}{\partial \alpha}+C_{D}\right) \alpha+\left(\frac{\partial^{2} C_{L}}{\partial \alpha^{2}}-C_{L}+2 \frac{\partial C_{D}}{\partial \alpha}\right) \alpha^{2} \\
& +\left(\frac{\partial^{3} C_{L}}{\partial \alpha^{3}}-3 \frac{\partial C_{L}}{\partial \alpha}+3 \frac{\partial^{2} C_{D}}{\partial \alpha^{2}}-C_{D}\right) \alpha^{3}+\mathrm{O}\left(\alpha^{4}\right)
\end{aligned}
$$

Similarly, the aerodynamic coefficients fitted with a cubic curve in the $z$-axis direction can be obtained.

$$
\begin{aligned}
& C_{z}=\left(\frac{\partial C_{D}}{\partial \alpha}+C_{L}\right) \alpha+\left(\frac{\partial^{2} C_{D}}{\partial \alpha^{2}}-C_{D}-2 \frac{\partial C_{L}}{\partial \alpha}\right) \alpha^{2} \\
& +\left(\frac{\partial^{3} C_{D}}{\partial \alpha^{3}}-3 \frac{\partial C_{D}}{\partial \alpha}-3 \frac{\partial^{2} C_{L}}{\partial \alpha^{2}}+C_{L}\right) \alpha^{3}+\mathrm{O}\left(\alpha^{4}\right)
\end{aligned}
$$

Let the coefficient of the primary term, secondary term and tertiary term of $\alpha$ in Eq. (21) be $\chi_{1}, \chi_{2}$, and $\chi_{3}$ respectively, leads to

$$
\begin{aligned}
& \frac{\partial C_{L}}{\partial \alpha}+C_{D}=\chi_{1}, \frac{\partial^{2} C_{L}}{\partial \alpha^{2}}-C_{L}+2 \frac{\partial C_{D}}{\partial \alpha}=\chi_{2} \\
& , \frac{\partial^{3} C_{L}}{\partial \alpha^{3}}-3 \frac{\partial C_{L}}{\partial \alpha}+3 \frac{\partial^{2} C_{D}}{\partial \alpha^{2}}-C_{D}=\chi_{3}
\end{aligned}
$$

Then, $C_{y}(\alpha)$ can be expressed as

$$
C_{y}=\chi_{1} \alpha+\chi_{2} \alpha^{2}+\chi_{3} \alpha^{3}
$$

Similarly, $C z(\alpha)$ can be expressed as

$C_{z}=v_{1} \alpha+v_{2} \alpha^{2}+v_{3} \alpha^{3}$ Where $\alpha=\alpha_{0}-\frac{\dot{v}}{U}$,then Eq. (17) and Eq. (18) can be
converted into

$p_{y}=\frac{1}{2} \rho U^{2} D\left[\chi_{1}\left(-\frac{\dot{v}}{U}\right)+\chi_{2}\left(-\frac{\dot{v}}{U}\right)^{2}+\chi_{3}\left(-\frac{\dot{v}}{U}\right)^{3}\right]$

$p_{z}=\frac{1}{2} \rho U^{2} D\left[v_{1}\left(-\frac{\dot{v}}{U}\right)+v_{2}\left(-\frac{\dot{v}}{U}\right)^{2}+v_{3}\left(-\frac{\dot{v}}{U}\right)^{3}\right]$

When $\alpha$ is $55^{\circ}$, the first, second, and third derivatives of the aerodynamic coefficients are calculated, respectively, then substituting these derivatives into Eq. (24) and Eq. (25), it can obtain that

$$
\begin{aligned}
& C_{y}=-0.96060 \alpha-1.40716 \alpha^{2}+97.62315 \alpha^{3} \\
& C_{z}=2.39795 \alpha-7.00826 \alpha^{2}-119.95612 \alpha^{3}
\end{aligned}
$$

Similarly, when $\alpha$ is $180^{\circ}$, it can obtain that

$$
\begin{aligned}
& C_{y}=-1.86364 \alpha+11.04465 \alpha^{2}+144.17126 \alpha^{3} \\
& C_{z}=0.49898 \alpha+7.80258 \alpha^{2}-39.21599 \alpha^{3}
\end{aligned}
$$

By substituting Eq. (26) into Eq. (15), then a new galloping equation of the conductor considering the influences of aerodynamic loads in the $y$-axis direction can be obtained.

$$
\begin{aligned}
& b_{1} \ddot{q}_{2}+\left(b_{2}+b\right) \dot{q}_{2}+b_{4} q_{2}+b_{5} q_{2}^{2}+b_{6} q_{3}^{2} \\
& +b_{8} q_{2}^{3}+b_{9} q_{2} q_{3}^{2}+b_{10} \dot{q}_{2}^{2}+b_{11} \dot{q}_{2}^{3}=0
\end{aligned}
$$

Where 
$b=\int_{0}^{l}-\frac{1}{2} \rho U^{2} D\left(-\frac{\alpha_{1}}{U}\right) \psi_{2}(x)^{2} \mathrm{~d} x$,

$b_{10}=\int_{0}^{l}-\frac{1}{2} \rho U^{2} D\left(\frac{\alpha_{2}}{U^{2}}\right) \psi_{2}(x)^{3} \mathrm{~d} x$,

$b_{11}=\int_{0}^{l}-\frac{1}{2} \rho U^{2} D\left(-\frac{\alpha_{3}}{U^{3}}\right) \psi_{2}(x)^{4} \mathrm{~d} x$,

By substituting Eq. (27) into Eq. (16), then a new galloping equation of the conductor considering the influences of aerodynamic loads in the z-axis direction can be obtained.

$$
\begin{aligned}
& c_{1} \ddot{q}_{3}+c_{2} \dot{q}_{3}+c_{3} q_{3}+c_{5} q_{2} q_{3}+c_{6} q_{2}^{2} q_{3} \\
& +c_{7} q_{3}^{3}+c_{8} \dot{q}_{2}+c_{9} \dot{q}_{2}^{2}+c_{10} \dot{q}_{2}^{3}=0
\end{aligned}
$$

\section{Where}

$$
\begin{aligned}
& c_{8}=\int_{0}^{l}-\frac{1}{2} \rho U^{2} D\left(-\frac{\beta_{1}}{U}\right) \psi_{2}(x) \psi_{3}(x) \mathrm{d} x, \\
& c_{9}=\int_{0}^{l}-\frac{1}{2} \rho U^{2} D\left(\frac{\beta_{1}}{U^{2}}\right)\left[\psi_{2}(x)\right]^{2} \psi_{3}(x) \mathrm{d} x, \\
& c_{10}=\int_{0}^{l}-\frac{1}{2} \rho U^{2} D\left(-\frac{\beta_{1}}{U^{3}}\right)\left[\psi_{2}(x)\right]^{3} \psi_{3}(x) \mathrm{d} x,
\end{aligned}
$$

\subsection{Characteristics of Galloping}

The physical parameters of conductor are shown in Table. 4 , and mode shapes are $\psi_{2}(x)=\sin (\pi x / l)$ and $\psi_{3}(x)=\sin (\pi x / l)$.

Table 4 Physical parameters

\begin{tabular}{|c|c|c|}
\hline Notation & Units & For line \\
\hline$A E$ & $10^{6} \mathrm{~N}$ & 13.30 \\
\hline$d$ & $10^{-3} \mathrm{~m}$ & 18.80 \\
\hline$H$ & $10^{3} \mathrm{~N}$ & 21.73 \\
\hline$f_{y}$ & $10^{-2}$ & 0.08 \\
\hline$f_{z}$ & $10^{-2}$ & 3.79 \\
\hline$m$ & $\mathrm{~kg} \mathrm{~m}^{-1}$ & 1.53 \\
\hline$l$ & $\mathrm{~m}$ & 300 \\
\hline
\end{tabular}

Substituting mode shapes and physical parameters into the galloping equation of iced conductor, the galloping displacement when $\alpha$ is $55^{\circ}$ or $180^{\circ}$ can be obtained as shown in Fig. 20 and Fig. 21.

For comparing the differences between amplitude and phase of iced quad bundle conductor at different angles of attack, the galloping displacement is drawn by taking the data of steady state in Fig. 20 and Fig. 21 above.

From Fig. 20 to Fig. 23, it can be obtained that the amplitude in the z-axis direction is much smaller than that in the $y$-axis direction when $\alpha$ is $55^{\circ}$ and $180^{\circ}$. And the differences for time between the z-axis direction and the $y$-axis direction of the quad bundle conductor to reach the stable state is not significant, which is about 50s. It can also be seen from Fig. 20(c) and Fig. 21(c) that the displacement in the z-axis direction is large at the beginning of galloping, the displacement in the $y$-axis direction increases with the increasing of time gradually, finally the displacement in the $y$-axis direction would be far greater than the displacement in the z-axis direction. For that, at the beginning of the galloping of conductor, the conductor is affected by the wind loads in the z-axis direction, then the displacement in the $z$-axis direction would be generated under the action of wind loads. When the displacement in the z-axis direction is generated, the $y$-axis direction would start to gallop slowly because of the influences of the aerodynamic loads on the negative slope, so the displacement of conductor is mainly represented by the displacement in the z-axis direction at the beginning of galloping and the displacement in the $y$-axis direction at the end of galloping.

\section{CONClusion}

(1) For the influences of wake effects, there are some differences between the aerodynamic coefficients of each sub-conductor of iced quad bundle conductor and the equivalent aerodynamic coefficients at the central axis of quad bundle conductor. Under the different wind speed, it can obtain the higher the wind speed is, the smaller the aerodynamic coefficients are.

(2) The Den Hartog coefficient of quad bundle conductor reaches the maximum value at both ends of the curve of aerodynamic coefficients and reaches the minimum value in the middle of the curve of aerodynamic coefficients. While the Den Hartog coefficient of iced single conductor reaches the maximum when $\alpha$ is $150^{\circ}$ or $220^{\circ}$, and reaches the minimum value in the middle of the curve of aerodynamic coefficients. With the increasing of wind speed, the values of the Den Hartog coefficient of iced quad bundle and single conductor would decrease, that is to say, the higher the wind speed is, the more likely the Den Hartog galloping would occur.

(3) The unstable range of Nigol galloping for iced quad bundle conductor is wider than that for iced single conductor. For most of the values of Nigol coefficients of single and quad bundle conductor are negative, which also directly shows that the torsional effect of iced conductor shouldn't be ignored in the actual engineering. The higher the wind speed is, the smaller the Nigol coefficient of iced quad bundle and single conductor is, and the Nigol galloping would occur. 


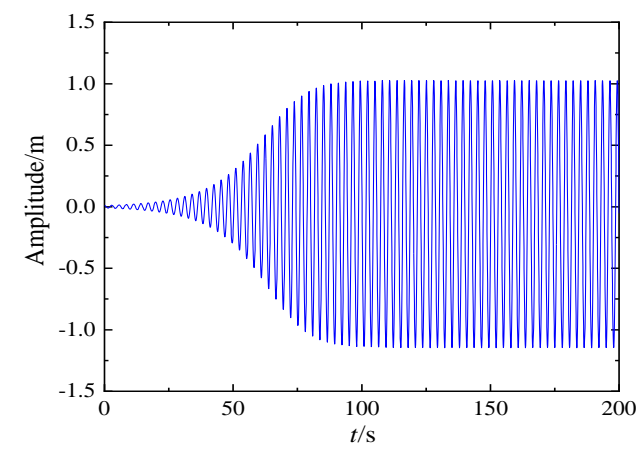

(a) Displacement in the $y$-axis direction

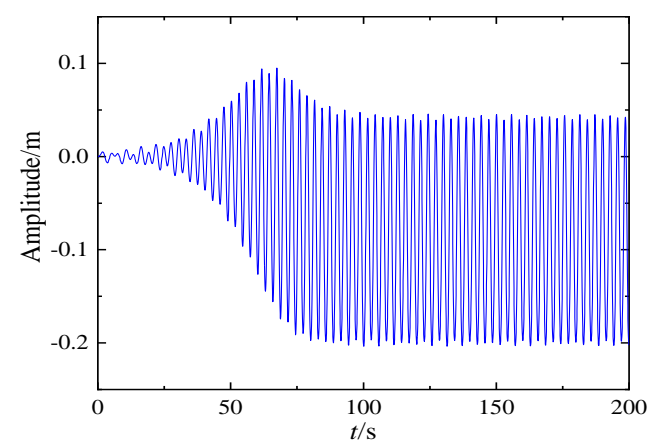

(b) Displacement in the z-axis direction

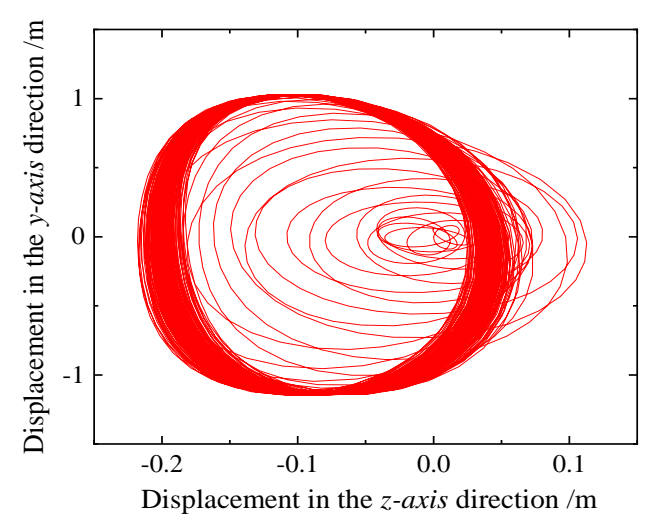

(c) Galloping trajectory

Fig. 20. Displacement of galloping at the angle of attack of $55^{\circ}$.

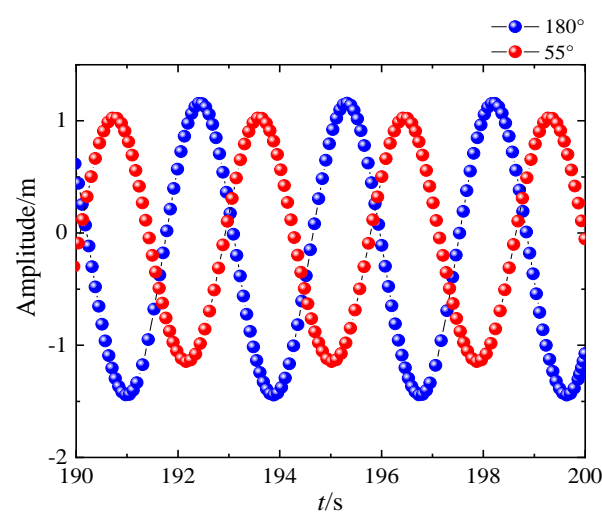

Fig. 22. Displacement in the $y$-axis direction.

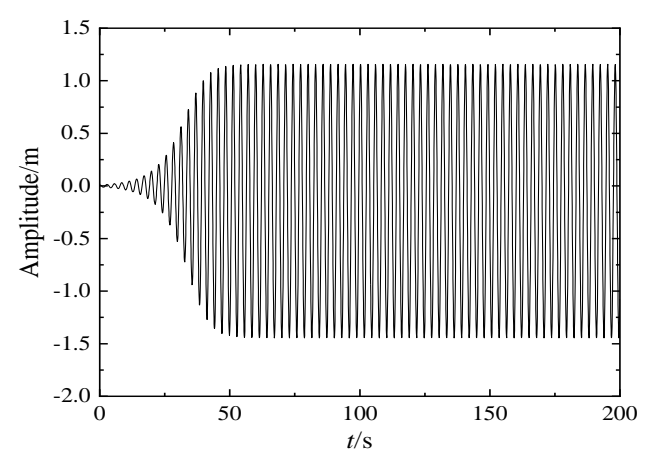

(a) Displacement in the $y$-axis direction

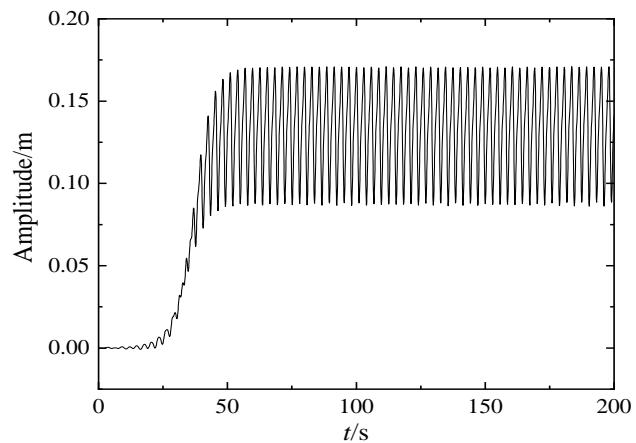

(b) Displacement in the z-axis direction

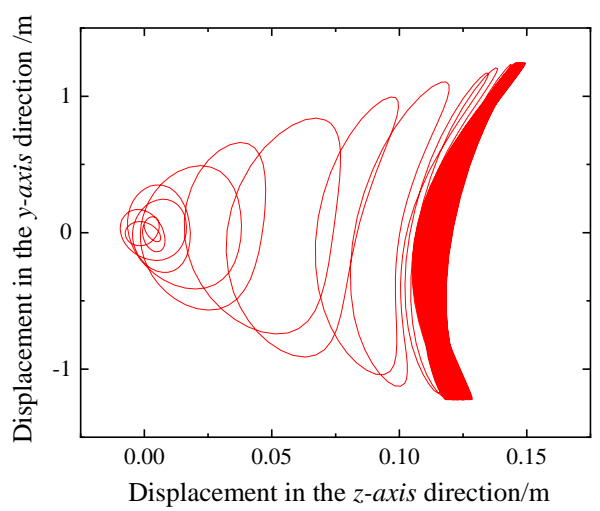

(c) Galloping trajectory

Fig. 21. Displacement of galloping at the angle of attack of $180^{\circ}$.

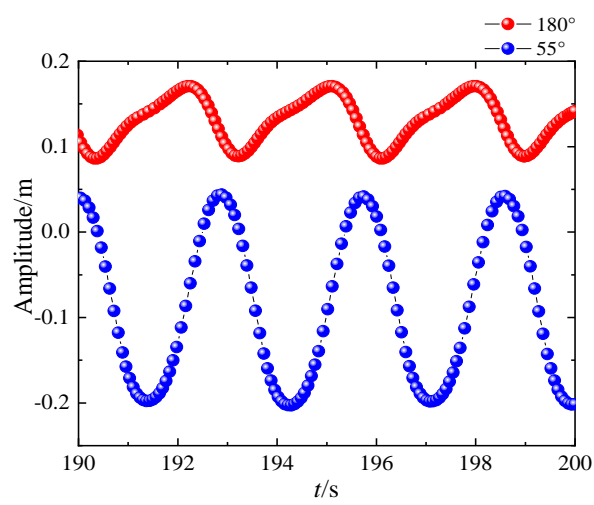

Fig. 23. Displacement in the $z$-axis direction. 
(4) The displacement in the y-axis direction is much smaller than that in the $z$-axis direction at the beginning of galloping, and the period would remain unchanged after the conductor is located at steady state. With the increasing of time, the displacement in the $y$-axis direction increases, and when the conductor is located at stable state, the displacement in the $y$-axis direction would be far greater than the displacement in the z-axis direction.

\section{FUNDING}

This work was financially supported by the National Natural Science Foundation of China (51507106 and 51308570), Cutting Edge Project of Chongqing Science and Technology Commission (cstc2017jcyjAX0246) and the Graduate Research and Innovation Project of Chongqing (cys 19240).

\section{REFERENCES}

Braun, A. L. and A. M. Awruch (2005). Aerodynamic and aeroelastic analysis of bundled cables by numerical simulation. Journal of Sound and Vibration 284(1-2), 5173.

Cai, M., Q. Xu, L. Zhou, X. Liu and H. Huang (2019) Aerodynamic Characteristics of Iced 8-bundle Conductors under Different Turbulence Intensities. KSCE Journal of Civil Engineering 23(6).

Cigre (2007). State of the art of conductor galloping. Technical Brochure No.322, TF B2. 11. O6.

Den Hartog, J. P. (1932). Transmission line vibration due to sleet. AIEE Transaction 4, 1074-1086.

Lee, C. L and N. C. Perkins (1992). Nonlinear oscillations of suspended cable containing a two-to-one internal resonance. Nonlinear Dynamics 3, 465-490.

Li, W. P. (1995). Static aerodynamic characteristics of the galloping of bundled iced power transmission lines. Acta Aerodynamica Sinica 1995(04), 427-434.

Li, W. P. (2000). Dynamic aerodynamic characteristics of the galloping of bundled iced power transmission lines. Acta Aerodynamica Sinica 2000(04), 413-420.

Liu, B., K. J. Zhu, X. M. Li and X. P. Zhan (2013). Hysteresis phenomenon in the galloping of the
D-shape iced conductor, Mathematical Problems in engineering, 1-12.

Liu, X. H., B. Yan, H. Y. Zhang and S. Zhou (2009). Nonlinear numerical simulation method for galloping of iced conductor. Applied Mathematics and Mechanics 30(4), 489-501.

Liu, X. H., Y. Hu and M. Q. Cai (2019). Free vibration analysis of transmission lines based on the dynamic stiffness method. Royal Society Open Science 6(3), 181354.

Lou, W. J., J. Yu, X. Jiang, X. H. Yang, M. Lu and Y. B. Shao (2017). Wind tunnel test and critical wind speed study for galloping of bundled iced conductors. Journal of Vibration Engineering 30(02), 280-289.

Lou, W., J. Lv, M. F. Huang, L. Yang and D. Yan (2014). Aerodynamic force characteristics and galloping analysis of iced bundled conductors. Wind and structures 18(2), 135-154.

Moghimi, P. and R. Rafee (2018). Numerical and Experimental Investigations on Aerodynamic Behavior of the Ahmed Body Model with Different Diffuser Angles. Journal of Applied Fluid Mechanics 11(4), 1101-1113.

Nigol, O. and P. G. Buchan (1981a). Conductor galloping 2: torsionail mechanism. IEEE Transactions on Power Apparatus and Systems 100(2), 708-720.

Nigol, O. and P. G. Buchan (1981b). Conductor galloping part I: Den-Hartog mechanism. IEEE Transactions on Power Apparatus and Systems PAS-100(2), 699-707.

Peng, J. N., D. L. Zhang, G. Y. Zhao and M. H. Bian (2014). Research. on regularity of the aerodynamic characteristics of iced conductor. Chinese Journal of Solid Mechanic 35 (S1): 202-207.

Wang, J., D. Liu, G. Gao, Y. Zhang and J. Zhang (2019). Numerical Investigation of the Effects of Sand Collision on the Aerodynamic Behaviour of a High-Speed Train Subjected to Yaw Angles. Journal of Applied Fluid Mechanics 12(2), 379-389.

Zhang, H. Y., B. Yan, S. Zhou, J. Hu and X. H. Liu (2011). Static test on aerodynamic character of iced quad bundled conductor. Acta Aerodynamica Sinica 29(02), 150-154.

Zhang, Q., N. Popplewell and A. H. Shah (2000). Galloping of bundle conductor. Journal of Sound and Vibration 234(1), 115-134. 